\title{
A
}

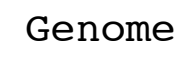

Protein functional

association

network

Species

of genomes

tree

E. Coli (C. tetani or H sp.)

Genome

Microbe-microbe

Genomes similarity functional association Phylogenetic

in STRING index index distance

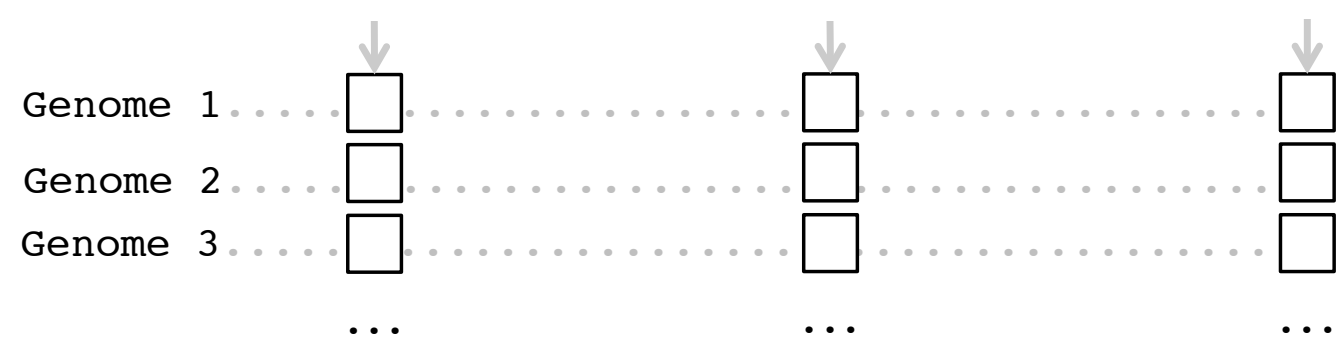

Genome $759 \ldots \ldots \ldots \ldots \ldots \ldots$

Scatterplots in Fig. 2

B

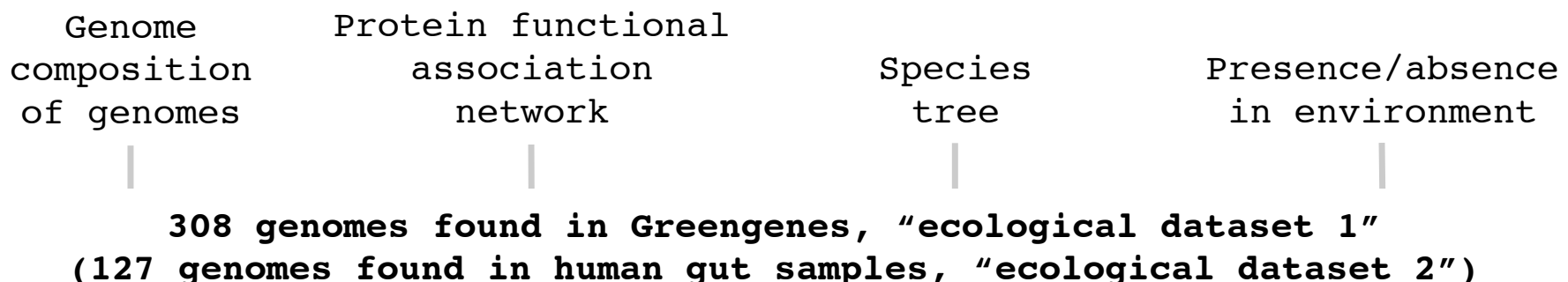

$308 \times 308$

(127 $\times 127)$

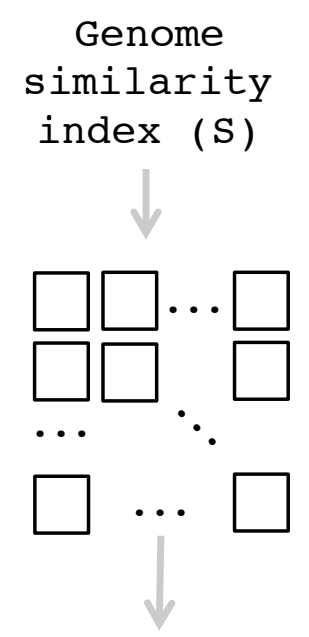

Microbe-microbe

Phylogenetic distance (D) index (A)

Mantel

$S=b * D+\varepsilon$ sociation

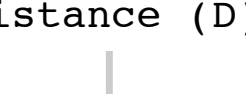

Co-occurrence (C)
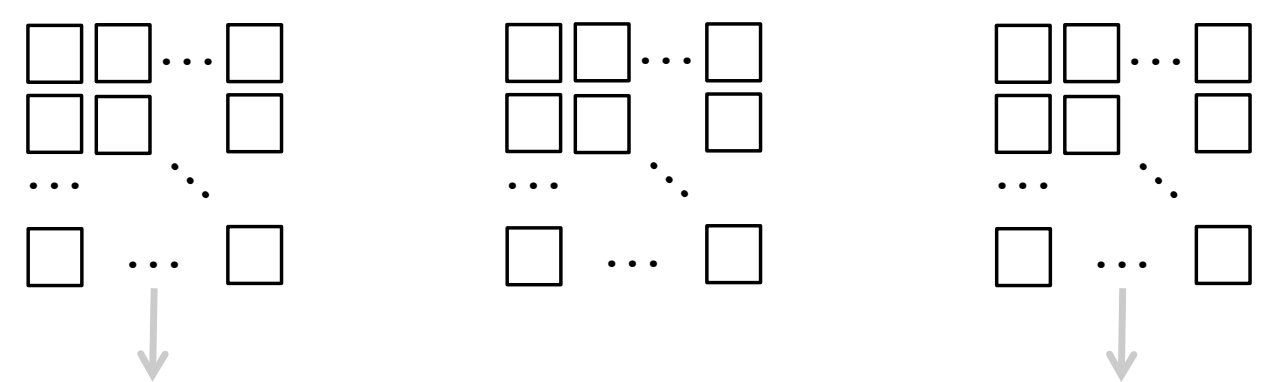

$C=b * D+\varepsilon$

$\varepsilon-$ adjusted $C$ Scatterplots

$\varepsilon-$ adjusted $A$

Matrix

$308 \times 308$

(127 $\times 127$ )
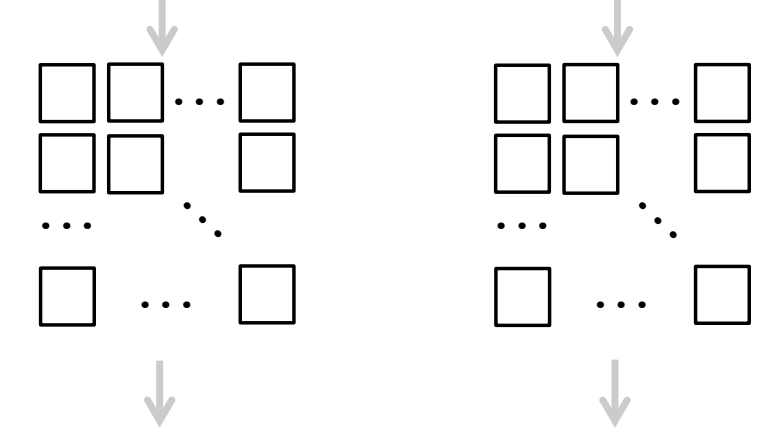

Adjusted co-occurrence (C)

versus Adjusted co-occurrence (C)

versus
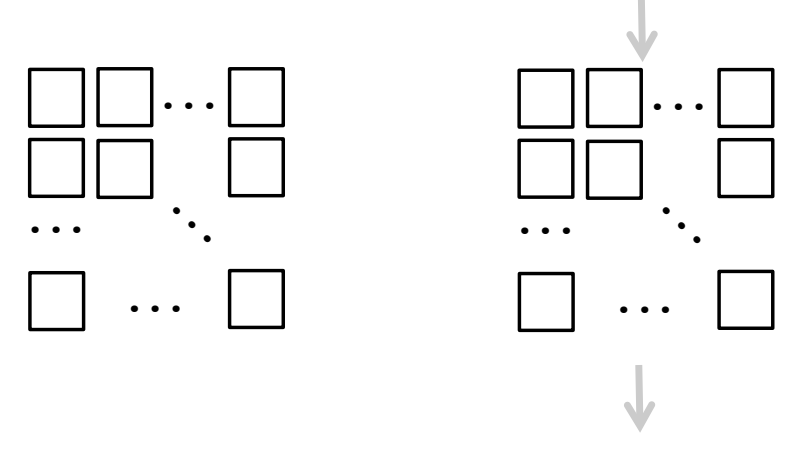

Adjusted genome content similarity (S)

Correlations

test of

correlation

$$
\text { associations (A) }
$$

and significance

in Fig. 3 and

Table 1

C

$\begin{array}{cccccc}\text { Genome } & \text { Protein functional } & \text { Metabolic } & \text { Metabolic } & \text { Presence/ } \\ \text { composition } & \text { association } & \text { KEGG } & \text { KEGG } & \text { Phylogeny } & \text { absence in } \\ \text { of genomes } & \text { network } & \text { pathways } & \text { pathways } & \text { of species environment }\end{array}$

\section{Obtained as} in panel $B$

Matrix $127 \times 127$
127 genomes found in human gut samples,

"ecological dataset 2"

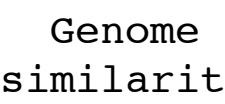
index (S)

Mantel regressions
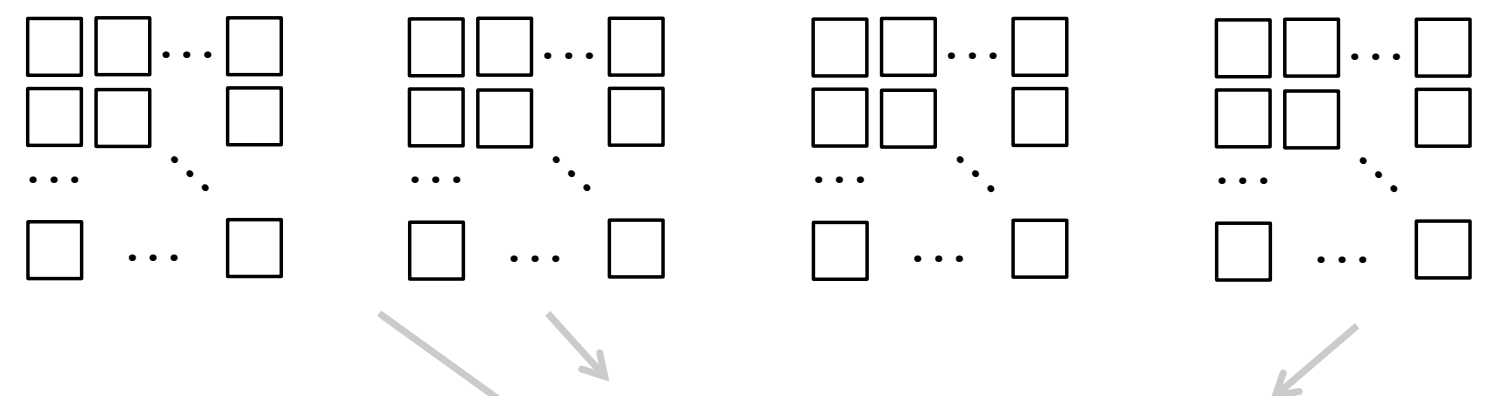

1. $C=b 0+b 1 * S+b 2 * D+\varepsilon$

2. $C=b 0+b 1 * A++b 2 * D+$

3. $C=b 0+b 1 * M C++b 2 * D+\varepsilon$

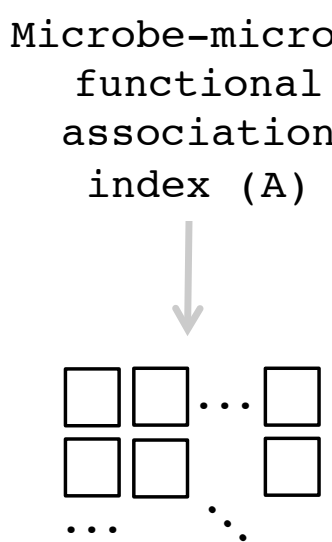

Metabolic competition Evolutionary index (MO) distance (D)

Cooccurrence (C)

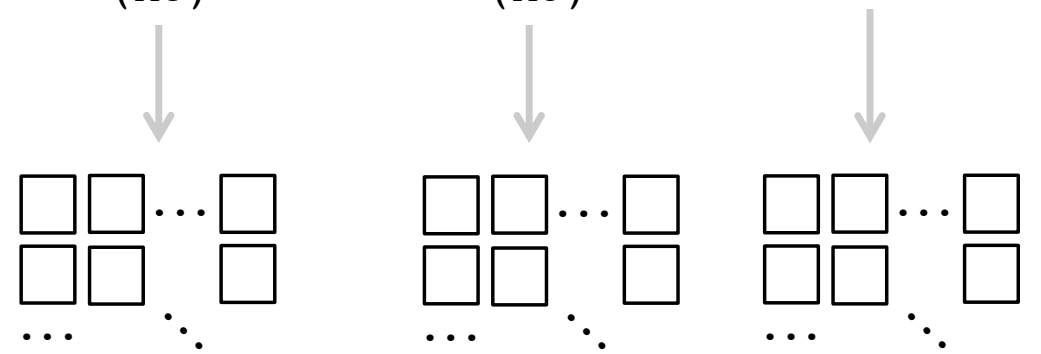

$\cdots \square$

environment

4. $C=b O+b 1 * M O++b 2 * D+\varepsilon$

5. $C=b 0+b 1 * S+b 1 * A+b 1 * M C+b 1 * M O+b 2 * D+\varepsilon$ 